\title{
Experimental tests of the impact of selected parameters on the indentation rolling resistances
}

\author{
Dariusz Woźniak ${ }^{1}$, Lech Gładysiewicz ${ }^{1}$, and Martyna Konieczna ${ }^{1, *}$ \\ ${ }^{1}$ Wroclaw University of Science and Technology, Faculty of Geoengineering, Mining and Geology, \\ 27 Wyb. Wyspianskiego St., 50-370 Wroclaw, Poland
}

\begin{abstract}
Belt conveyors are main part of transporting systems in mines and in many other branches of industry. During conveyor belt works different types of resistances are generated. Indentation rolling resistance is the most significant component of the resistances from the perspective of energy losses and it cause the biggest costs as well. According to latest state of analyses and measurements it is well known that theoretical rolling resistance were underestimated in comparison with the measured in-situ one. In this paper new method for determination indentation rolling resistance is presented. The authors compared theoretically and experimentally established damping factors. The relation between these two values enabled to obtain more precise equation for damping function. This function is one of the most important component in calculation of the rolling resistance. In new theoretical model value of rolling resistance is nearly twice higher than this used so far.
\end{abstract}

\section{Introduction}

Present-day belt conveyors are highly reliable machines capable of transporting materials at distances of several dozen kilometers, passing through curvatures and operating on inclined terrain. Special operating conditions do not affect their efficiency. Therefore, research in the field of belt conveyor transportation increasingly focuses on lowering the power consumption of belt conveyors while maintaining their capability to serve the same transport functions. Lowered power consumption of belt conveyors translates directly into the reductions of maintenance costs [1]. The lowering of power consumption, however, requires performing both theoretical analyses [2-4] and laboratory tests [5, 6]. The reduction of motion resistances, and hence the reduction of the energy absorbed by belt conveyors, remains the object of research in many countries [7, 8], as well as in Poland $[5,9,10]$. This paper offers a simple and inexpensive method of testing belt rolling resistance (also referred to as belt indentation resistance or indentation rolling resistance). The method allows the analysis of such factors as core design, cover thickness, ambient temperature, idler travel frequency, or load on the total value of rolling resistance. The analysis presented in this paper focuses on

\footnotetext{
* Corresponding author: martyna.konieczna@pwr.edu.pl
} 
how the frequency and speed of rolling the idler on the belt sample influence the belt's rolling resistance.

\section{Methods for Testing Belt Rolling Resistance}

The translational motion of a belt on a conveyor is accompanied by a number of physical phenomena which entail various forms of energy conversion. In the case of belt conveyors longer than $80 \mathrm{~m}$, main resistances are economically most important. The dominant component of main resistances are belt rolling resistances, which are related to a cyclical process of pressing the coat of an idler into the bottom cover of the belt at each support idler [11].

Indentation rolling resistances are investigated in many research centers and belt manufacturing companies worldwide. The main goal is to develop novel solutions which will lead to the reduction of motion resistances in conveyor belts, while retaining their strength parameters. The known and used methods for determining the bellt-on-idler rolling resistances include: 1) analytical methods based on the parameters of the bottom cover as calculated in laboratory tests, 2) actual measurements of belt rolling resistances in laboratory conditions and 3) actual measurements of belt rolling resistances in belt conveyor operating conditions [12].

The most widespread methods for laboratory measurements of indentation rolling resistances include methods developed at the University of Hannover [7, 13], at the Newcastle University [8] and the inclined plane method developed at Wroclaw University of Science and Technology [11]. The dimensions of the testing rigs used in the above methods necessitate the use of large sample test pieces having nominal length of $7.5 \mathrm{~m}$ and also impede tests in sub-zero temperatures. Moreover, the above methods do not allow tests with idler rolling frequencies typical of actual operating conditions of a belt conveyor.

This paper describes a test rig for determining conveyor belt rolling resistances, which allows a small-scale and inexpensive, yet precise measurement of resistance values. Smaller size belt samples allow the belt top cover to be removed with greater ease, and hence the core and the bottom cover can be tested separately. The tests can be performed at temperatures both above and below zero degrees Celsius, as well as at various load values and idler travel frequencies. Thus, the operation of a belt conveyor in actual mining conditions may be simulated in a number of variants. Research to date allowed precise adjustment of both the test method and the result analysis method [14].

\section{A new method for testing indentation rolling resistance}

The method has been developed at Machine Systems Division, Wroclaw University of Science and Technology, Faculty of Geoengineering, Mining and Geology. It consists in the measurement of rolling resistance during cyclical rolling of an idler on a belt sample approx. 400x60 mm in size. The test, in which the idler travels (passes) on the belt, takes a form reverse to actual conditions, in which it is the belt that passes on a series of idler sets. Notwithstanding, the physical phenomena involved in the process are identical. The main aim of the research was to develop a simple and inexpensive method for testing indentation rolling resistance, which would enable the analysis of how the resistance is influenced by such factors as temperature, load, idler travel frequency (indentation frequency), as well as belt design and bottom cover thickness. Small dimensions of the test rig allow placing it in a thermal chamber and conducting tests in various temperatures above and below zero degrees Celsius; in addition, small dimensions of test samples reduce the cost of tests (no need for 
long belt sections and splicing) and enable optimal selection of materials and the belt regarding the energy-efficiency of its design.

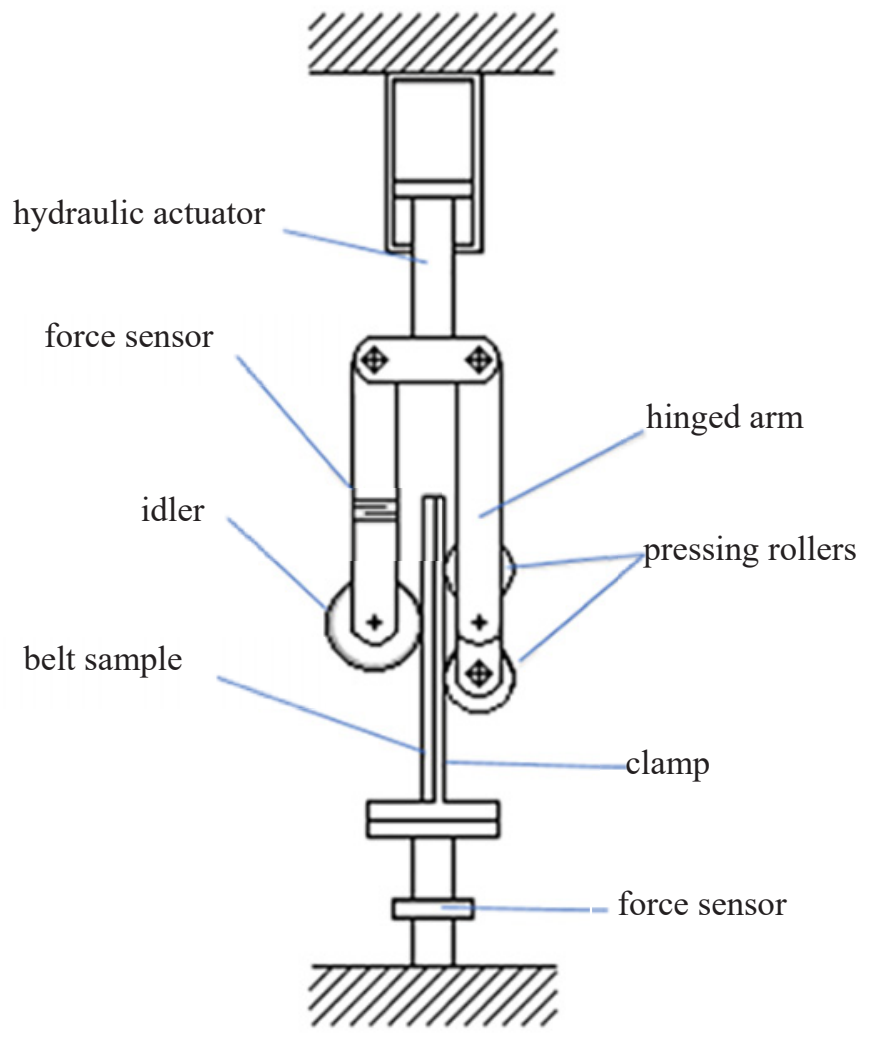

Fig 1. Diagram of a test rig for measuring indentation rolling resistances - small scale tests [4].

Figure 1 is the diagram of the test rig. After the top cover is removed, the belt sample is secured in the clamp (and tensioned). The idler rolls on the test piece. The idler is pressed against the belt using a tensioning system equipped with a force sensor. The rolling resistance is measured with force sensors. To compensate for the transverse forces transmitted to the force sensor and the piston rod of the hydraulic actuator, additional rollers were used, which always roll on the metal part of the clamp. Both the idler and the additional rollers are guided with hinged arms. The idler's reciprocating movement is effected by a hydraulic actuator. Prior to measurements, own resistances of the test rig must be determined. This is done by first assembling the test rig without the belt sample inserted. Own resistances are determined for the idler rolling on the metal clamp, at a set temperature and at a set load. In the next step, the measurements are performed with the belt sample inserted. The difference between motion resistances recorded with the sample and those recorded without the sample correspond to the rolling resistance of idler on belt [5]. 


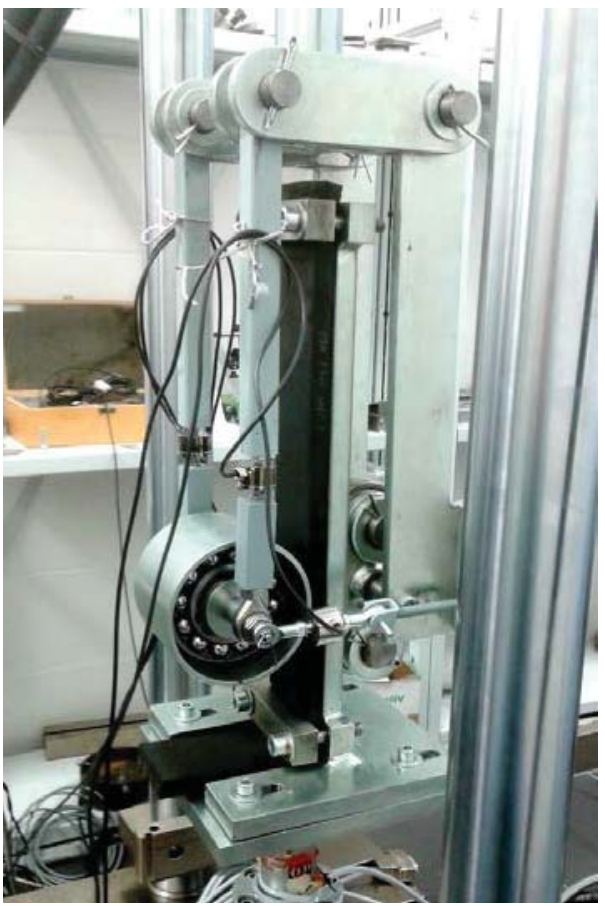

Fig. 2. Test rig for measuring indentation rolling resistances $(\mathrm{PWr})[12]$.

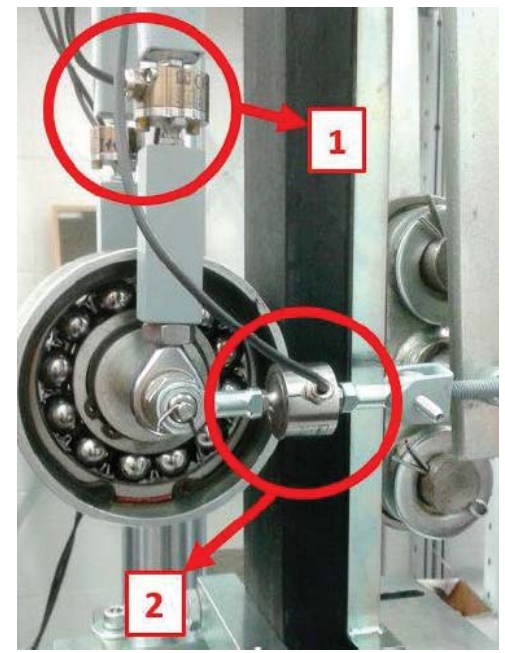

Fig. 4. The measurement system of the test rig for measuring indentation rolling resistances (PWr) [12].

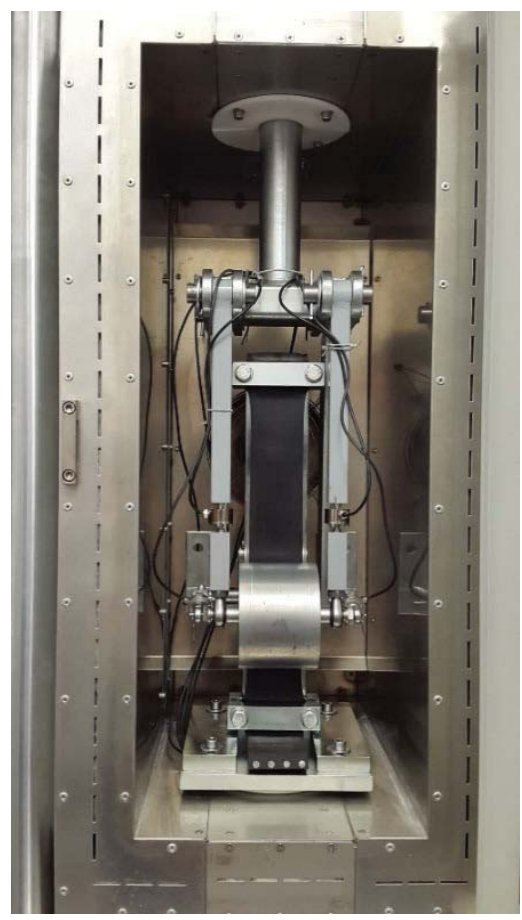

Fig. 3. Test rig for measuring indentation rolling resistances in a thermal chamber (PWr) [12].

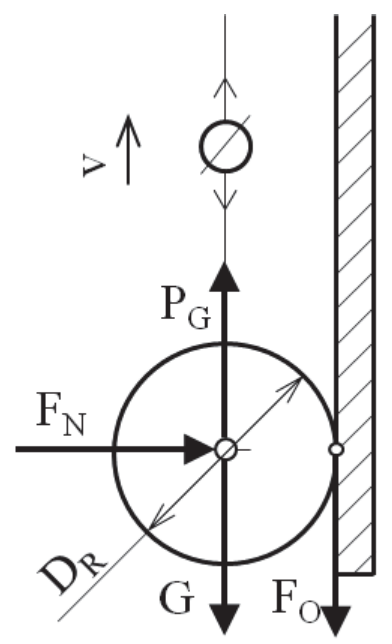

Fig. 5. System of forces during the steady motion of the idler upwards (PWr) [12]. 


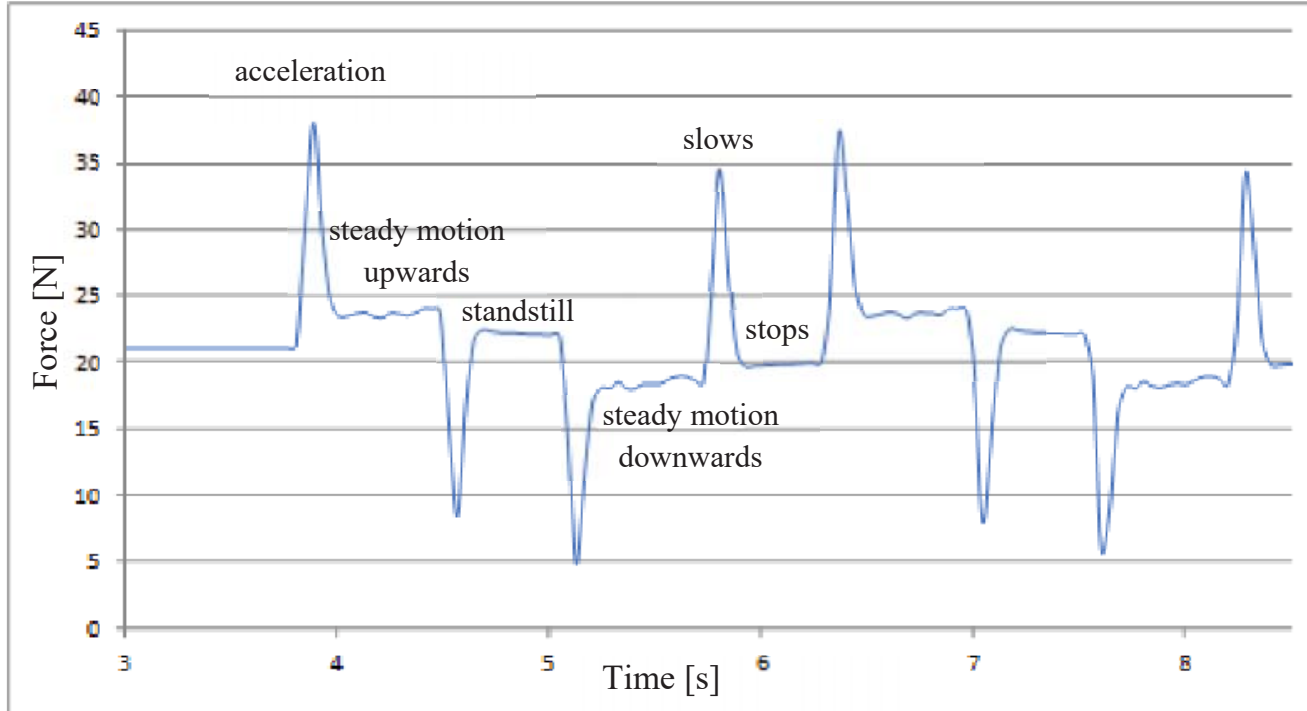

Fig. 6. Sample plot of forces recorded for the idler rod during tests of rolling resistance of idler on belt [12].

The idler travels on the belt sample upwards and downwards with constant speed and stops to a standstill at return points. Drawing force is recorded with force sensors (1) shown in Fig. 4, located in the idler arms. Pressing force of the idler on the belt is recorded with force sensors (2), located in the roller rods. Fig. 6 shows a sample plot of force recorded for the idler rods during the tests. A single motion cycle of the idler (one motion upwards and one motion downwards) can be divided into several stages, which are represented in the plot of force recorded for the idler rods. In the first stage, the idler accelerates to a set speed here a force peak occurs which is related to the acceleration of a given idler mass and to the setting in rotary motion of the mass of idler's moving part. In the following stage, the idler travels on the belt with a steady motion upwards - here the force is stable. In the third stage the idler slows and stops to a standstill - here the force in the rod decreases rapidly. As the idler remains in standstill for a brief time, the force becomes stable, and in the following stages the idler accelerates again to a set speed, moves with a steady motion downwards, slows and stops at the bottom return point [12].

The calculation of idler motion resistance requires considering the courses of forces during constant motion upwards and downwards. Fig. 5 shows the system of forces during the steady motion of the idler upwards. Steady motion is characterized by a balance of forces, and hence the force recorded for the idler rod during the upward motion $\left(P_{G}\right)$ is balanced by force of gravity $G$ and by motion resistances $F_{O}$. In the case of the idler's steady motion downwards, only the vector of force for motion resistances will change its sense. The following equation can be constructed:

$$
\begin{aligned}
& -P_{G}+F_{O}+G=0 \\
& -P_{D}-F_{O}+G=0
\end{aligned}
$$

Thus, a motion resistance equation can be derived:

$$
F_{O}=\frac{P_{G}-P_{D}}{2}
$$


where

$P_{G}-$ force in the idler rod during the upward motion, in $\mathrm{N}$

$P_{D}-$ force in the idler rod during the downward motion, in $\mathrm{N}$

$G$ - force of gravity, in N

$F_{O}-$ motion resistances, in $\mathrm{N}$

As the idler travels on the belt, motion resistances comprise idler rotational resistance $F_{R}$ and idler rolling resistances on belt (idler indentation resistances) $F_{E}$. In the case when the idler travels on the clamp without a belt, the rolling resistance values for a steel idler traveling on a steel surface are negligible and thus motion resistance $F_{O S}$ may be assumed to be equal to idler rotational resistance $F_{R}$. Idler rolling resistance on belt (idler indentation resistance) $F_{E}$ will be:

$$
\begin{aligned}
& F_{E}=F_{O}-F_{O S} \\
& F_{E}^{\prime}=\frac{F_{E}}{b_{R}}
\end{aligned}
$$

where

$F_{E}$ - idler rolling resistance on belt, in $\mathrm{N}$

$F^{\prime}{ }_{E}$ - idler unit rolling resistance on belt, in $\mathrm{N} / \mathrm{m}$

$F_{O S}-$ motion resistance in a test without a belt, in $\mathrm{N}$ thickness), in $\mathrm{m}$

$b_{R}$ - the length of the contact line between the belt and the idler coat (sample

Initial tests were performed for an ST 2500 steel-cord conveyor belt with the bottom cover $7 \mathrm{~mm}$ in thickness. The idler was pressed against the belt with force $F_{N}=250 \mathrm{~N}$, which results in a unit load per $1 \mathrm{~m}$ of the length of the contact line between the belt and the idler coat having value $F_{N}{ }^{\prime}=4.2 \mathrm{kN} / \mathrm{m}$. The idler had diameter $D_{R}=108 \mathrm{~mm}$. The idler traveled on the belt with speed $v=250 \mathrm{~mm} / \mathrm{s}$ and frequency $f=1.2 \mathrm{~Hz}$. The tests were performed in ambient temperature $T=20^{\circ} \mathrm{C}$. The idler traveled on the belt in 50 cycles ( 1 cycle understood as a motion upwards and a motion downwards). During the test, the recorded values included time, force in idler rods and pressing force of idler on belt. In the following step, the same conditions and parameters were used to perform measurements without the belt: the idler traveled on the steel clamp. The measurement results for both cases are shown in Fig. 7. Indentation unit rolling resistance for the tested belt is $F^{\prime}{ }_{E}=27,1 \mathrm{~N} / \mathrm{m}$. 


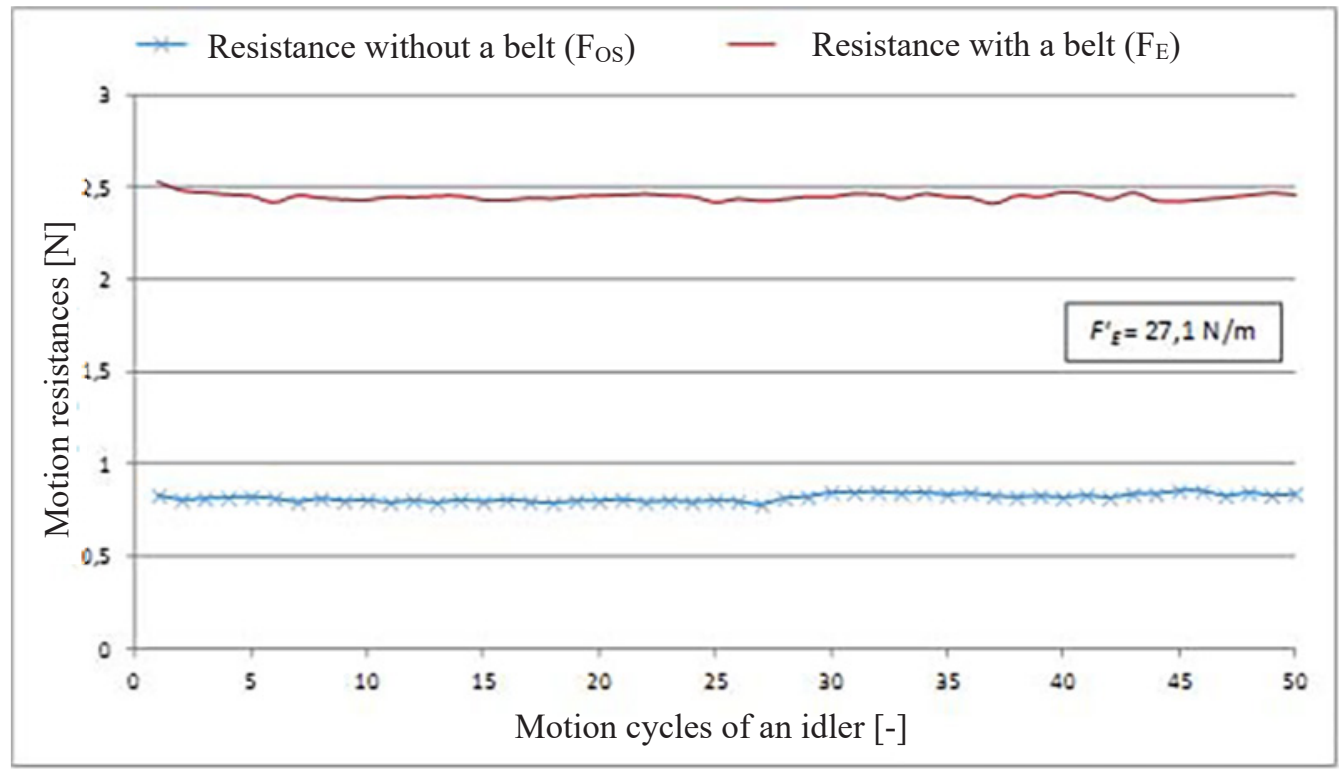

Fig. 7. Measurement results for idler rolling resistance on belt ST 2500 (pulley cover thickness $7 \mathrm{~mm}$, load $-4.2 \mathrm{kN} / \mathrm{m}$, idler diameter $-108 \mathrm{~mm}$, speed $-250 \mathrm{~mm} / \mathrm{s}$, travel frequency $-1.2 \mathrm{~Hz}$, temperature $\left.-20^{\circ} \mathrm{C}\right)[12]$

\section{Tests of the relationship between rolling resistance and the selected motion parameters of the idler}

\subsection{Relationship between rolling resistance and idler travel frequency}

In accordance with the methodology described in the previous chapter, a series of rolling resistance tests was performed for two belts: ST 2500 - steel-cord belt described by the manufacturer as a belt with low rolling resistances (energy-efficient) and ST 2000 - a regenerated steel-cord belt. In both cases the tests were performed for various idler travel frequencies, in the range from $0.2 \mathrm{~Hz}$ to $1.4 \mathrm{~Hz}$. For each of the samples, a total number of 7 various rolling resistance values was determined, which correspond to various frequencies. The tests were performed at a constant idler travel speed of $250 \mathrm{~mm} / \mathrm{s}$, as the standstill time of the idler at the return point can be regulated (Fig. 6). 


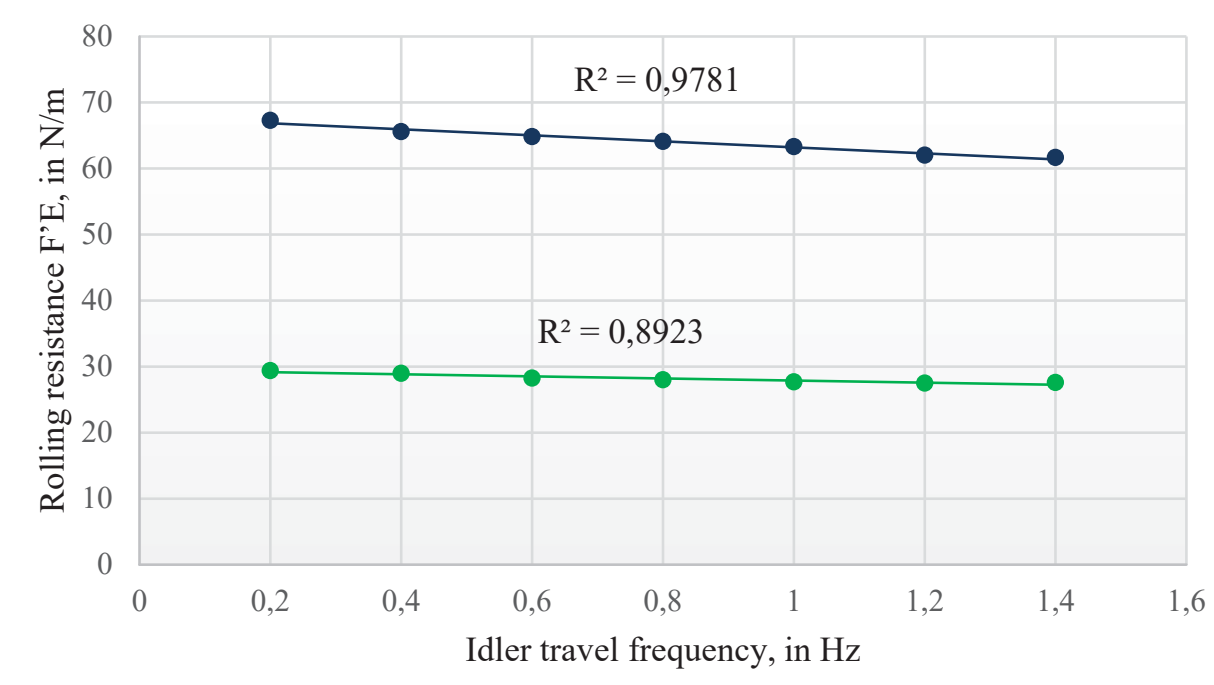

- ST 2500 energy-efficient belt • ST 2000 regenerated steel-cord belt

Fig. 7. Relationship between rolling resistance and idler travel frequency

As expected, the energy-efficient belt showed a significantly (over 200\%) lower rolling resistance than the regenerated belt. In both cases, the relationship between the measured resistances and idler travel frequencies are linear and have a coefficient of determination equal to 0.8923 for the ST 2500 belt and equal to 0.9781 for the ST 2000 belt. Determination at this level implies that the selected characteristics offer highly precise representation of the investigated relationships. For both the energy-efficient and the regenerated belt, rolling resistances decreased as the travel frequencies increased. Albeit, the decrease for the regenerated belt was faster than for the energy-efficient belt.

\subsection{Relationship between rolling resistance and idler travel speed}

Another investigated parameter was the speed at which the idler traveled on the belt sample. Here the tests were also performed on the ST 2000 regenerated belt and on the ST 2500 energy-efficient belt. In the case of belt ST 2000, the measurements were performed for four different idler travel speeds, in the range from $100 \mathrm{~mm} / \mathrm{s}$ to $250 \mathrm{~mm} / \mathrm{s}$ (speed was incremented at $50 \mathrm{~mm} / \mathrm{s}$ intervals). In the case of belt ST 2500,7 measurements were performed for different idler travel speeds, in the range from $50 \mathrm{~mm} / \mathrm{s}$ to $350 \mathrm{~mm} / \mathrm{s}$ (speed was also incremented at $50 \mathrm{~mm} / \mathrm{s}$ intervals). All measurements were performed at a constant idler travel frequency equal to $0.25 \mathrm{~Hz}$. 


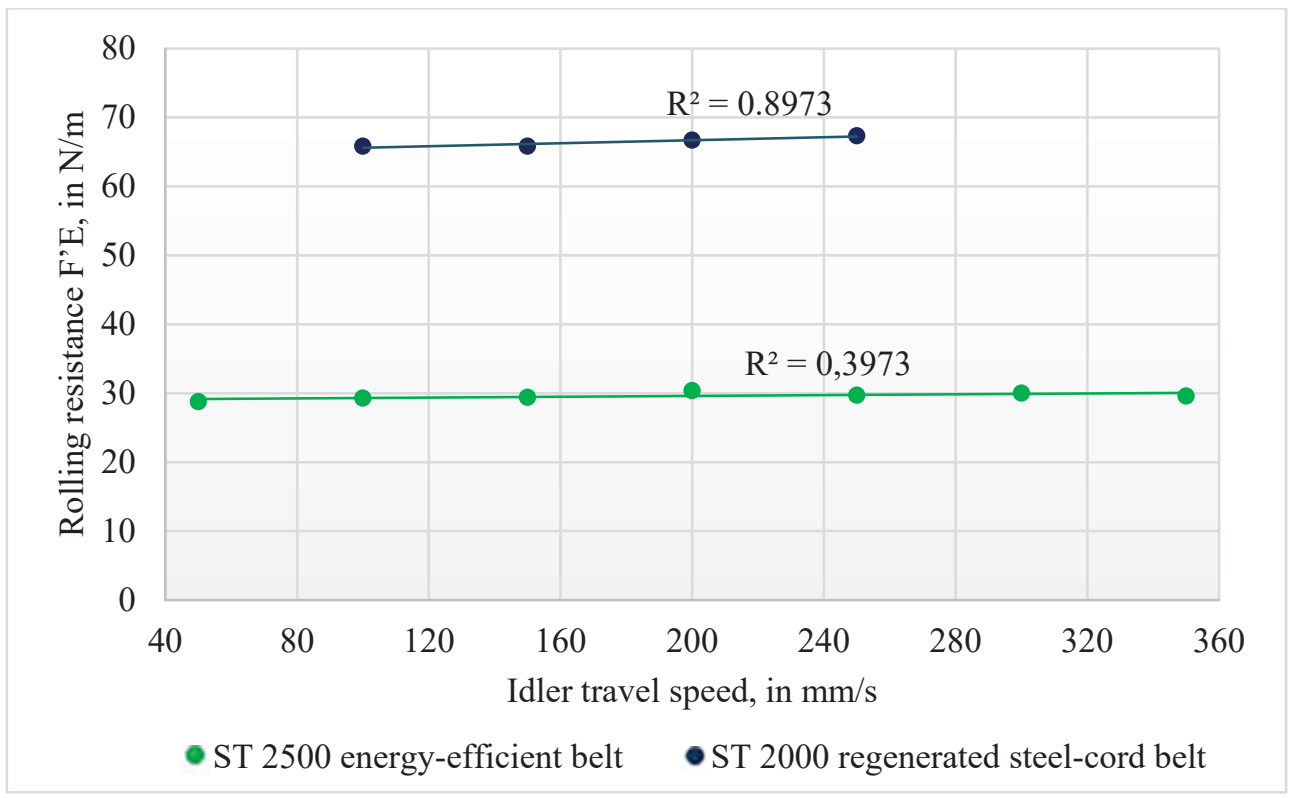

Fig. 8. Relationship between rolling resistance and idler travel speed

As was the case with the previous tests, here rolling resistances for the regenerated belt are also twice higher than for the energy-efficient belt. The values of rolling resistance increase together with increasing speed. These changes, however, have a distinctively smaller scale than the changes effected by the varying idler travel frequencies (which are practically negligible for the energy-efficient belt). This fact correlates with the results of theoretical analyses performed to date by researchers from a number of countries [2, 4], which assume that the influence of speed on rolling resistance is negligible. It also correlates with the results of experiments which show this influence to be limited [8]. However, in the case of the regenerated belt, which has higher rolling resistances, the range of resistance changes is greater than for the energy-efficient belt. Therefore, the influence of speed on the changes in rolling resistances depends on the elastic and damping properties of the rubber cover.

\section{Conclusions}

The new method for testing indentation rolling resistance enables an uncomplicated and inexpensive analysis of the influence of various belt motion parameters on rolling resistances. Research into the influence of idler travel frequency on rolling resistance was performed for the first time. Such research has not yet been described in literature.

The performed tests (4.1) show a significant influence of idler travel frequency on the rolling resistance measured on the belt. An increase in the frequency causes the resistance to decrease, which can be explained by reduced relaxation time of the rubber cover. In the case of the regenerated belt, the easured resistance was more than twice higher than in the case of the energy-efficient belt.

Tests performed for various idler travel speeds confirm that the influence of speed on rolling resistances is limited/negligible. Significantly, the above changes depend on the elastic and damping properties of the belt, which have the most significant influence on the rolling resistances generated as the idler travels on the belt (i.e. on the energy-efficiency of the belt). 
Financial support by the project: Research, diagnostics and optimization of conveyor belt systems No. 0401/0166/16 and Grant no. 0401/0128/17.

\section{References}

1. J. Kudelko, Gospodarka Surowcami Mineralnymi - Mineral Resources Management, Volume 32, Issue 4, 157-179 (2016)

2. C. Spaans, Bulk Solids Handling Vol. 11 No.4, 809-826 (1991)

3. X. Qiu, Journal of Engineering Mechanics, Vol. 132 No.11, 1241-1251 (2006)

4. L. Gładysiewicz, Przenośniki taśmowe Teoria i obliczenia, Oficyna Wydawnictwo Politechniki Wrocławskiej, Wrocław (2003)

5. D. Woźniak, L. Gładysiewicz, M. Hardygóra, D. Kaszuba, W. Kisielewski, Stanowisko pomiarowe do badania oporu toczenia krążników, Patent PL223986 (2016)

6. R. Król, W. Kisielewski, D. Kaszuba, L. Gładysiewicz, Procedia: Earth and Planetary Science, WMESS Vol. 15, $712-719$ (2015)

7. T. Wennekamp, S. Hotte, S. Von Daacke, L. Schulz, L. Overmeyer, Bulk Solids Handling Vol. 32, Issue 6 (2012)

8. C. Wheeler, P. Munzenberger, International Materials Handling Conference (Beltcon 16) (2011)

9. M. Bajda, R. Król, Procedia: Earth and Planetary Science, WMESS vol. 15, 702-711 (2015)

10. R. Król, W. Kisielewski, Mining Science - Fundamental Problems of Conveyor Transport, vol. 21(2), 61-72 (2014)

11. M. Hardygóra, H. Komander, M. Bajda, Górnictwo i Geoinżynieria, Wydawnictwo AGH, Rok 35, Zeszyt 3/1, Kraków (2011)

12. L. Gładysiewicz, D. Woźniak, M. Konieczna, Transport Przemysłowy i Maszyny Robocze, no 2, 6-10 (2017)

13. DIN 22123: 2012-10 Fördergurte - Gurtbreitenbezogener Eindrückrollwiderstand von Fördergurten - Anforderungen, Prüfung (2012)

14. D. Woźniak, L. Gładysiewicz, M. Hardygóra, D. Kaszuba, W. Kisielewski, Transport Przemysłowy i Maszyny Robocze, no 3, 6-10 (2015) 